\title{
EFEITO DE DIFERENTES NÍVEIS DE FÓSFORO EM SOLUÇÃO NUTRITIVA E NO SOLO NO COMFORTAMENTO DE CULTIVARES DE TRIGO ${ }^{1}$ )
}

\author{
CARLOS EDUARDO DE OLIVEIRA CAMARGO (2), Seçāo de Arroz e Cereais de Inverno \\ Instituto Agronomico.
}

\section{RESUMO}

Foram estudados dez cultivares de trigo quanto à sua eficiência na utilização de fósforo em solução nutritiva contendo quatro niveis de $\mathrm{P}(0 ; 3,875 ; 7,75$ e $15,5 \mathrm{mg} / \mathrm{litro})$, mantendo-se a temperatura constante de $25 \pm 1^{\circ} \mathrm{C}$ e $\mathrm{o} \mathrm{pH}$ das soluçóes igual a 4,0 por um período de quinze dias. A eficiência da utilização de fósforo para cada cultivar em cada uma das concentraçóes desse elemento foi expressa pela quantidade de matéria seca da parte aérea e pela proporção entre a quantidade de matéria seca da parte aérea e a quantidade de fósforo nela presente. Os cultivares IAC-5, IAS-20, BH-1146 e IAC-17 foram eficientes na utilização de fósforo em soluções contendo $3,875 \mathrm{mg}$ /itro de P; IAC-18, IAC-15 e IAC-13 apresentaram-se como moderadamente eficientes, e Siete Cerros, Alondra-S-46 e INIA-66, como ineficientes. Os cultivares IAC-5, IAC-18 e INIA-66 responderam aumentando suas produçōes de matéria seca da parte aérea, à medida que o teor de $\mathrm{P}$ das soluções se elevou de 0 a 15,5mg/litro; IAS-20, IAC-13, Siete Cerros e Alondra-S-46 apresentaram moderada resposta e BH-1146, IAC-17 e IAC-15 não responderam. Os cultivares IAC-5 e IAC-17 foram estudados em vasos contendo solo nos quais foram empregadas três doses de adubação com superfosfato simples $\left(0,30\right.$ e $60 \mathrm{~kg} / \mathrm{ha}$ de $\left.\mathrm{P}_{2} \mathrm{O}_{5}\right)$ combinadas com três doses de calcário dolomítico $(0,4$ e $8 \mathrm{t} / \mathrm{ha})$. Os dois cultivares

(1) Com recursos complementares do Acordo do Trigo entre as Cooperativas de Produtores Rurais do Vale do Paranapanema e a Secretaria de Agricultura e Abastecimento, através do Instituto Agronômico. Recebido para publicação a 4 de agosto de 1982.

(2) Com bolsa de suplementaçáo do CNPq. 
responderam à adubação com $\mathrm{P}_{2} \mathrm{O}_{5}$ para os três níveis de calcário em relação à prođução de matéria seca da parte aérea aos trinta dias após a germinação, porém o IAC-5 apresentou maiores respostals em relação ao IAC-17. Considerando fixo um mesmo nível de $\mathrm{P}_{2} \mathrm{O}_{5}$, verificou-se que os dois cultivares responderam à aplicação de calcário até a dosagem de 4 t/ha. Os dois cultivares aumentaram a produção de grãos por planta quando foram aplicadas doses crescentes de $P_{2} O_{5}$, mantendo-se constante a dose de calcário de 4t/ha, porém as grandes respostas ocorreram quando foram comparadas as dosagens de 0 e $30 \mathrm{~kg}$ de $\mathrm{P}_{2} \mathrm{O}_{5} / \mathrm{ha}$, independentemente da quantidade de calcário aplicada. O cultivar IAC-5 estudado em soluções nutritivas contendo diferentes doses de $\mathrm{P}$ apresentou maior eficiência na utilização desse elemento quando comparado com o IAC-17, nas doses mais baixas de P. A mesma conclusão foi obtida, empregando-se solo com baixos teores desse elemento. Em virtude de os dados poderem ser obtidos em pouco tempo no laboratório, evidenciou-se a vantagem do emprego de soluções nutritivas para o estudo da eficiência na utilização e absorção de fósforo por cultivares de trigo, alem de possibilitar seu uso num programa de melhoramento genético onde muitas linhas estiverem envolvidas.

\section{INTRODUÇÃO}

Em vastas áreas do território brasileiro, incluindo grande parte do Estado de São Paulo, os solos apresentam baixa disponibilidade de fósforo. Trabalhos desenvolvidos pelo Instituto Agronômico (Campinas) mostraram grandes respostas na produção de trigo com a aplicação de adubação fosfatada $(1,2,4,9)$.

Com a crescente necessidade de,produzir alimentos, e em particular o trigo, em nossas condições, há pelo menos duas alternativas para a solução desse problema. Uma delas seria o tradicional suprimento de nutrientes através da aplicação de fertilizantes e de corretivos, e, outra, selecionar linhagens adaptadas a teores médios a baixos de nutrientes no solo, porém com maior eficiência na sua absorção e utilização.

GABELMAN (5), GERLOFF (6) e WHITEAKER et alii (10), estudando 54 cultivares de feijão em soluções nutritivas contendo $2 \mathrm{ppm}$ de $\mathbf{P} /$ planta, separaram os cultivares nas seguintes classes: eficientes, moderadamente eficientes e ineficientes, com base no peso seco da parte aérea e na proporção da eficiência da utilização de fósforo (PER), definida como miligrama de matéria seca produzida por miligrama de $\mathrm{P}$ no tecido. Os citados autores também verificaram, estudando os mesmos cultivares em soluções contendo 31 e $62 \mathrm{ppm}$ de $\mathrm{P} /$ planta, que alguns deles apresentavam aumento de crescimento quando o $\mathrm{P}$ da solução aumentava para os níveis mais elevados e outras linhas não mostravam respostas.

Em milho foi observado que três cultivares apresentaram diferentes capacidades de absorver $\mathbf{P}$ de culturas de areia com uma 
mesma concentração desse elemento (8). Resultados semelhantes foram obtidos com soja onde foram estudados 44 cultivares, que foram agrupados em cinco categorias de acordo com suas respostas a altas concentrações de $\mathrm{P}$ na solução nutritiva (7).

O presente trabalho tem por objetivos: a) estudar o comportamento de cultivares de trigo de interesse para o Estado de São Paulo em solução nutritiva e no solo contendo níveis baixos de fósforo; b) estudar a resposta desses cultivares a vários níveis de fósforo nas mesmas condições.

\section{MATERIAL E MÉTODOS}

\subsection{Ensaio de cultivares de trigo em solução nutritiva}

O delineamento estatístico empregado foi blocos ao acaso com parcelas subdivididas com duas repetiçōes, onde as parcelas foram compostas por quatro concentrações de fósforo $(0 ; 3,875 ; 7,75$ e $15,5 \mathrm{mg}$ / litro) e as subparcelas, por dez chltivares de trigo, a saber: $\mathrm{BH}-1146$, IAC-5, IAC-13, IAC-15, IAC-17, IAC-18, Alondra-S-46, IAS-20, INIA-66 e Siete Cerros.

As sementes desses cultivares foram cuidadosamente lavadas com uma solução de hipoclorito de sódio a $10 \%$ e colocadas para germinar em caixas de Petri por 24 horas. Após esse tempo, as radículas estavam iniciando a emergência.

Foram escolhidas trinta sementes uniformes de cada cultivar e colocadas sobre a superfície de quatro telas de náilon que foram adaptadas sobre quatro vasilhas plásticas de 8,3 litros de capacidade contendo soluções nutritivas, de maneira que as sementes fossem mantidas úmidas e as radículas emergentes tocassem na solução, tendo, pois, um pronto suprimento de nutrientes.

A concentração final das soluções das quatro vasilhas plásticas foi a seguinte: $\mathrm{Ca}\left(\mathrm{NO}_{3}\right)_{2} 4 \mathrm{mM} ; \mathrm{MgSO}_{ \pm} 2 \mathrm{mM} ; \mathrm{KNO}_{3} 4 \mathrm{mM}$; $\left(\mathrm{NH}_{4}\right)_{2} \mathrm{SO}_{4} \quad 0,435 \mathrm{mM} ; \mathrm{CuSO}_{4} \quad 0,3_{\mu} \mathrm{M} ; \mathrm{MnSO}_{4} 2_{\mu} \mathrm{M} ; \mathrm{ZnSO}_{4} \quad 0,8 \mu \mathrm{M}$; $\mathrm{NaCl} 30_{\mu} \mathrm{M}$; Fe-CYDTA $10 \mu \mathrm{M}, \mathrm{Na}_{2} \mathrm{MoO}_{4} 0,1 \mu \mathrm{M}$ e $\mathrm{H}_{3} \mathrm{BO}_{3} \quad 10_{\mu} \mathrm{M}$. Em cada uma das quatro soluções, foi adicionado $\mathrm{KH}_{2} \mathrm{PO}_{4}$ de modo que fossem obtidas soluções com $0 ; 3,875 ; 7,75$ e $15,5 \mathrm{mg}$ /litro de $\mathrm{P}$. O $\mathrm{OH}$ das soluções foi previamente ajustado para 4,0, com solução de $\mathrm{H}_{2} \mathrm{SO}_{4} 1 \mathrm{~N}$, e mantido constante por ajustamentos diários durante todo o experimento. As soluções foram continuamente arejadas $e$ as vasilhas plásticas contendo as soluções colocadas em banho-maria com temperatura de $25 \pm 1{ }^{\circ} \mathrm{C}$ dentro do laboratório. As plantas foram mantidas com luz fluorescente no período total do experimento.

As plantas desenvolveram-se nessas condições por quinze dias, findos os quais foram retiradas das soluções, determinando-se o cresci- 
mento da raiz primária central de cada plântula, e medindo-se em milímetros seu comprimento. Em seguida, foram separadas as raízes das partes aéreas das trinta plantas de cada cultivar submetido a crescimento em soluções contendo diferentes concentrações de fósforo. As raízes e as partes aéreas de cada tratamento foram colocadas para secar em estufa com temperatura de $45^{\circ} \mathrm{C}$ por cinco dias. No final desse período, foi determinado o peso seco em miligramas das raízes e das folhas e o peso seco total das plântulas. As folhas (parte aérea) secas foram analisadas quimicamente quanto aos teores de $\mathrm{P}, \mathrm{N}, \mathrm{K}, \mathrm{Ca}, \mathrm{Mg}$ e S.

Para expressar a eficiência da utilização de fósforo de cada cultivar submetido a crescimento em soluções nutritivas contendo diferentes concentrações desse elemento, foi utilizado o mesmo critério citado por WHITEAKER et alii (10), portanto, a proporção da eficiência da utilização de fósforo (PER) foi calculada pela divisão entre o peso seco da parte aérea em miligrama e a quantidade em miligrama de $\mathbf{P}$ presente nesses tecidos.

\section{2. Ensaio de cultivares de trigo em vasos}

Trinta e seis vasos plásticos medindo aproximadamente $25 \mathrm{~cm}$ de altura e $20 \mathrm{~cm}$ de diâmetro, cheios com uma quantidade igual de solo hidromórfico de altitude, de área ainda não cultivada, procedente da Estação Experimental de Itararé, foram divididos em nove grupos de quatro, recebendo os tratamentos citados no quadro 1. Anteriormente ao plantio, os solos dos vasos, dependendo dos tratamentos, foram bem misturados com adubo fosfatado (superfosfato simples com $20 \%$ de $\mathrm{P}_{2} \mathrm{O}_{5}$ ) e com calcário dolomítico e mantidos úmidos por noventa dias. Após esse período, foram retiradas amostras compostas dos solos dos vasos de mesmo tratamento, cujos resultados analíticos $\left({ }^{3}\right)$ se encontram no quadro 1.

Foram estudados dois cultivares: IAC-5, tolerante à toxicidade de $\mathrm{Al}^{3+}$, e IAC-17, de média tolerância a esse elemento em soluçōes nutritivas e no solo (3).

O delineamento estatístico utilizado foi blocos ao acaso com 18 tratamentos (dois cultivares $\mathrm{x}$ três doses de $\mathrm{P}_{2} \mathrm{O}_{\overline{3}} \times$ três doses de calcário) e duas repeticões.

Em cada vaso, foram plantadas 14 sementes que originaram igual número de plantas. Os vasos foram colocados no telado à prova de pássaros, localizado no Centro Experimental de Campinas, distantes um do outro $30 \mathrm{~cm}$. Foi usada uma bordadura, empregando-se vasos com solo de mesma origem plantados com sementes do cultivar BH-1146.

(3) Análises efetuadas pela Seção de. Fertilidade do Solo, Instituto Agronômico. 


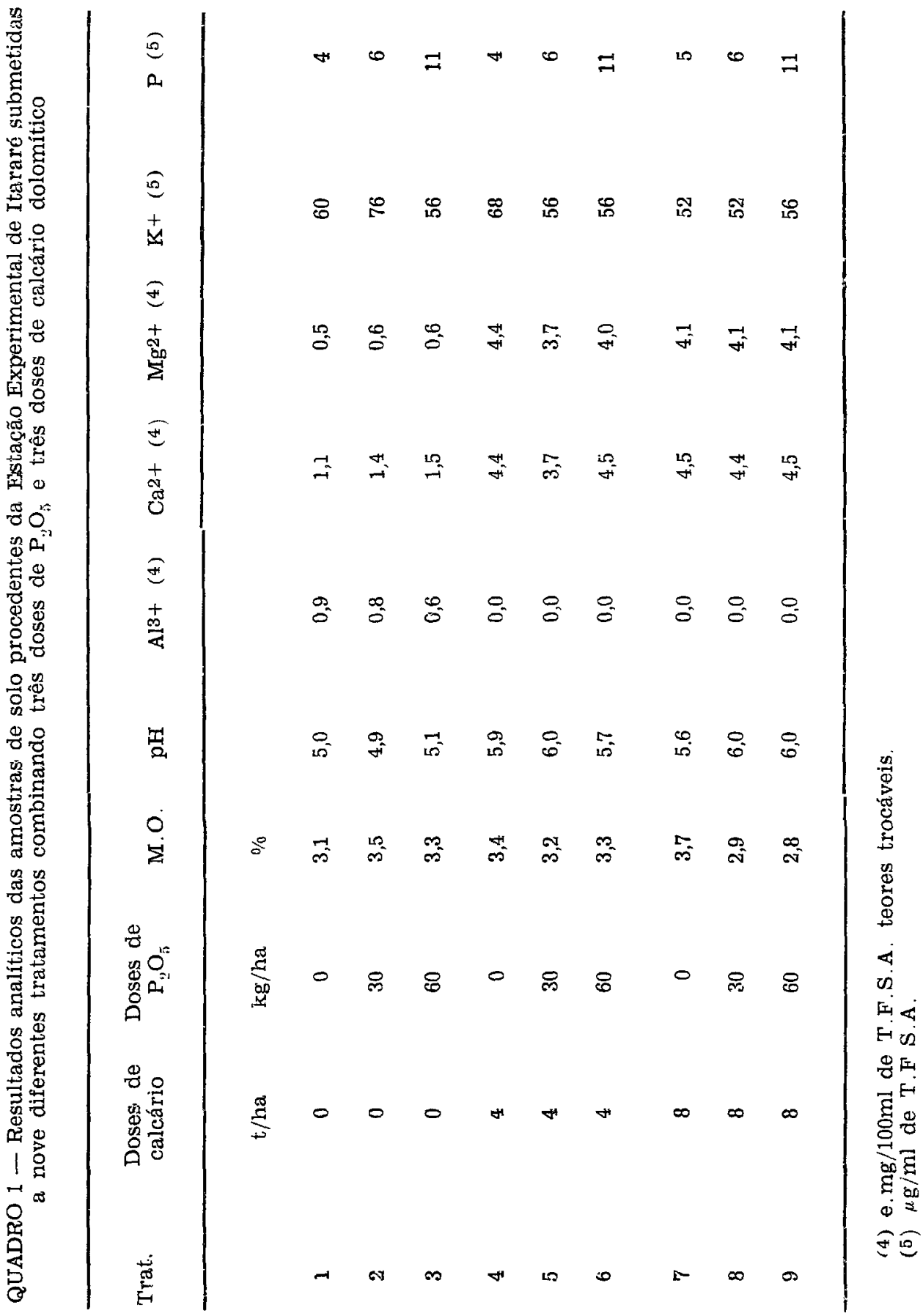


Quando as plantas dos vasos submetidos a diferentes tratamentos estavam com trinta dias de germinação, foram retiradas sete plantas de cada vaso, lavadas e colocadas em estufa com temperatura de $45^{\circ} \mathrm{C}$ para cinco dias para secagem. O material proveniente da parte aérea foi pesado e enviado para análise química em relação aos teores de $\mathrm{P}$, $\mathrm{K}, \mathrm{Ca}, \mathrm{Mg}$ e Al.

As plantas remanescentes, em número de sete em cada vaso, foram cultivadas até à maturação completa, quando foram coletados os seguintes caracteres agronômicos na base de plantas individuais :

Altura da planta: medida em centímetro da superfície do solo até a ponta da espiga do colmo mais alto, excluindo as aristas.

Número de espigas por planta: considerando o número de colmos com espigas férteis.

Número de espiguetas: computando como o número de espiguetas do colmo principal.

Comprimento da espiga: medindo o comprimento em centímetro da espiga do colmo principal da planta, excluindo as aristas.

Número de grãos por espiga : contando o número total de grãos da espiga principal da planta.

Número de grãos por espigueta: calculando pela divisão do número total de grãos da espiga principal pelo número total de espiguetas da mesma espiga.

Produção de grãos:pesando em gramas a produção total de grãos de cada planta.

A média das sete plantas de cada vaso foi submetida à análise da variância, para todos os caracteres agronômicos estudados.

\section{RESULTADOS E DISCUSSÃO}

\subsection{Ensaio de cultivares de trigo em solução nutritiva}

A produção média da matéria seca total, da parte aérea e das raízes, bem como o comprimento médio das raízes e os teores médios de $\mathrm{P}, \mathrm{N}, \mathrm{K}, \mathrm{Ca}, \mathrm{Mg}$ e $\mathrm{S}$ na matéria seca da parte aérea das trinta plantas, de cada um dos dez cultivares de trigo estudados durante quinze dias, em soluções nutritivas contendo 3,875 e $15,5 \mathrm{mg} /$ litro de $\mathrm{P}$ encontram-se respectivamente nos quadros 2 e 3 .

Os resultados mostraram que, quando foi utilizado o nível de $3,875 \mathrm{mg} /$ litro de $\mathrm{P}$, a média da produção de matéria seca da parte aérea de trinta plântulas do cultivar IAC 15 foi $1.380 \mathrm{mg}$, diferindo pelo teste 


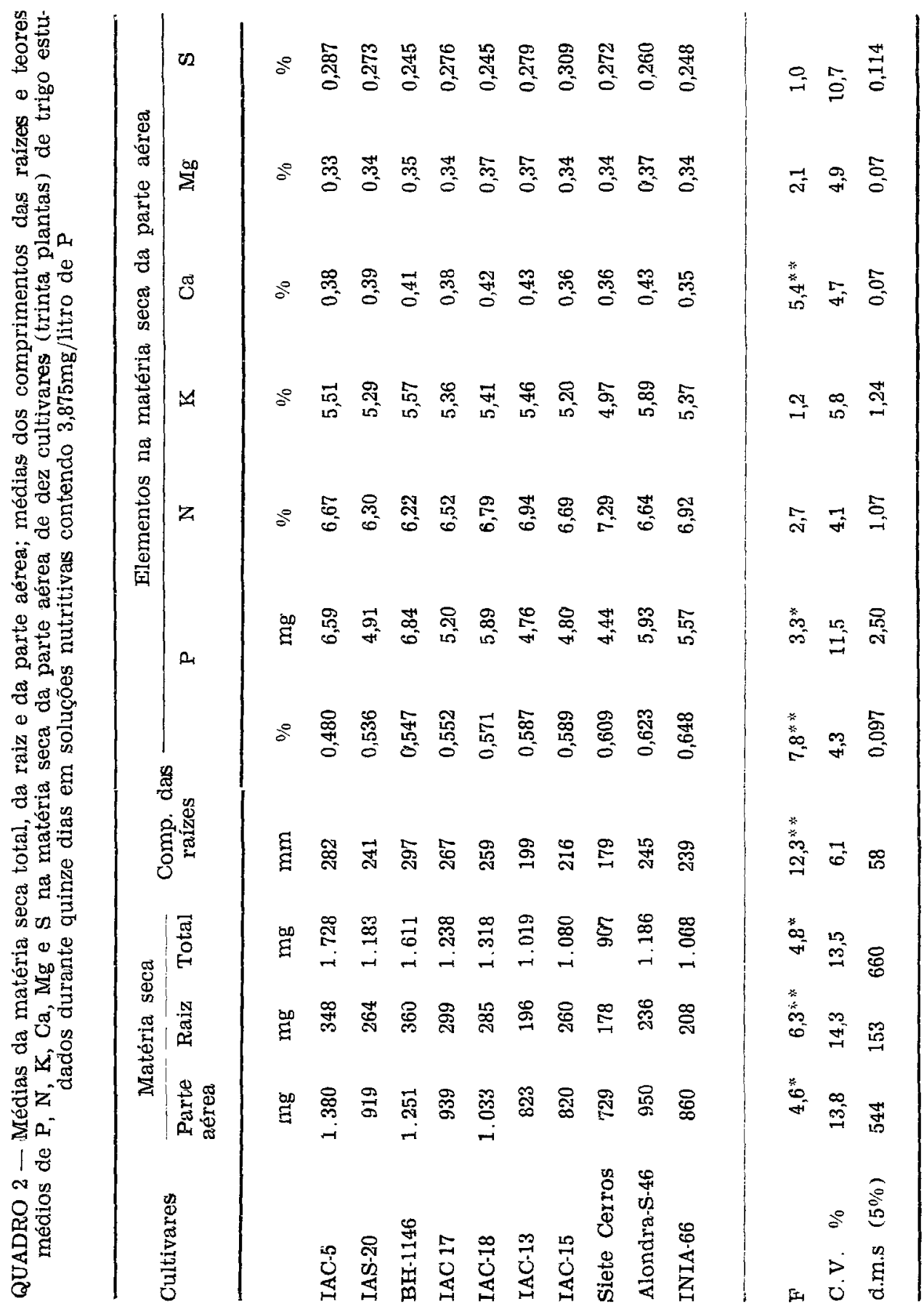




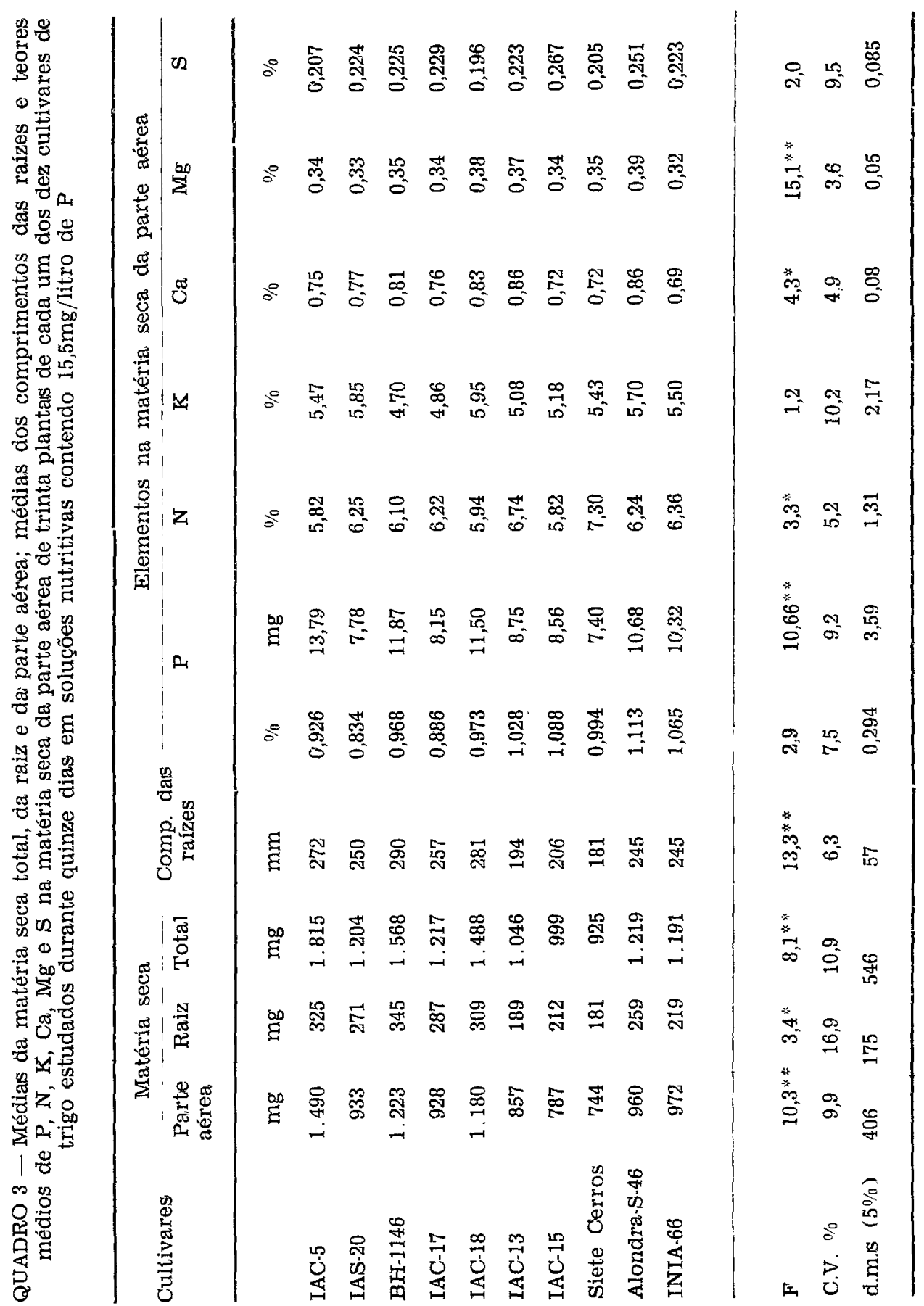


de Tukey ao nível de 5\% dos cultivares Siete Cerros, IAC-13 e IAC-15, não diferindo, porém, dos demais cultivares. Em relação à matéria seca e comprimento das raízes, o cultivar $\mathrm{BH}-1146$ foi o que apresentou maior produção, diferindo de Siete Cerros e IAC-13, não diferindo dos demais.

Considerando o nível de $15,5 \mathrm{mg} /$ litro de $\mathrm{P}$ na solução, verificou-se que o cultivar IAC-5 apresentou $1.490 \mathrm{mg}$ de matéria seca da parte aérea, diferindo pelo teste de Tukey dos cultivares: IAS-20, IAC-17, IAC-13, IAC-15, Siete Cerros, Alondra-S-46 e INIA-66, não diferindo, porém, de: BH-1146 e IAC-18. Em relação à produção de matéria seca das raízes, não hove diferença significativa entre os cultivares pelo teste de Tukey. BH-1146 apresentou maior crescimento médio de raízes do que IAC-13, IAC-15 e Siete Cerros.

O crescimento relativo dos cultivares variou com a concentração de fósforo nas soluções; entretanto, a capacidade de responder ao $\mathrm{P}$ foi específica de cada cultivar. IAC-5, IAS-20, IAC-18, IAC-13, Siete Cerros, Alondra-S-46 e INIA-66 aumentaram sua produção de matéria seca da parte aérea quando foram cultivadas em solução contendo $15,5 \mathrm{mg} /$ litro de $\mathrm{P}$, porém BH-1146, IAC-17 e IAC-15 apresentaram redução dessa produção nas mesmas condições.

Os teores de $\mathbf{P}$ em porcentagem na matéria seca da parte aérea aumentaram para todos os cultivares à medida que as doses de $\mathrm{P}$ das soluções foram aumentadas de 0 para $15,5 \mathrm{mg} /$ litro de P (Figura 1).

Para o nível de 3,875mg/litro de $P$, verificou-se que o 'INIA-66' foi o que mostrou maior teor de $\mathrm{P}$, diferindo do 'IAC-5', porém não dos demais cultivares. Considerando o nível de $15,5 \mathrm{mg} /$ litro de $\mathrm{P}$, não foram verificadas diferenças significativas quanto ao teor de $\mathbf{P}$ entre os cultivares estudados. Esses resultados estão de acordo com os obtıdos por WHITEAKER et alii (10), pois a concentração de $\mathbf{P}$ foi mais baixa nas linhas de feijão eficientes na utilização do fósforo do que nas linhas ineficientes, considerando-se os baixos níveis desse nutriente nas soluções.

Em relação aos teores em porcentagem de $\mathrm{N}, \mathrm{K}, \mathrm{Mg}$ e $\mathrm{S}$, houve poucas variaçōes na matéria seca da parte aérea dos cultivares em estudo, à medida que variaram as concentrações de fósforo das soluções, porém fez exceção o teor de $\mathrm{Ca}$ em porcentagem, que aumentou para todos os cultivares à medida que se adicionaram quantidades crescentes de $\mathrm{P}$ nas soluções.

Os valores da proporção da eficiência na utilização de fósforo (PER) para todos os cultivares e para as diferentes concentrações de $\mathrm{P}$ nas soluções encontram-se na figura 2 e no quadro 4 . 


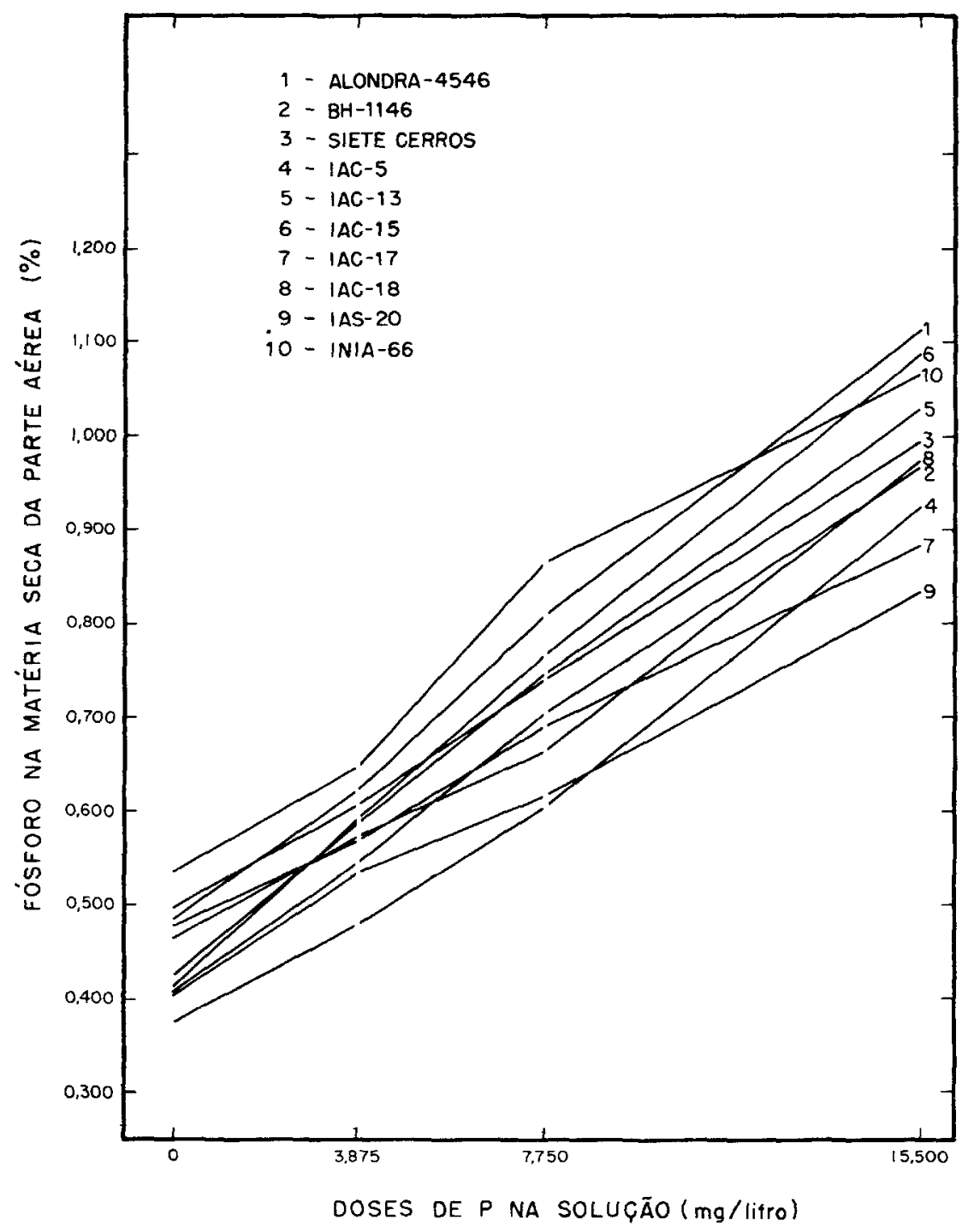

FIGURA 1 - Fósforo na matêria seca da parte aérea $(\%)$ das trinta plantas de cada um dos dez cultivares de trigo estudados durante quinze dias em soluções nutritivas contendo $0 ; 3,875 ; 7,75$ e $15,5 \mathrm{mg} /$ litro de $\mathrm{P}$. 


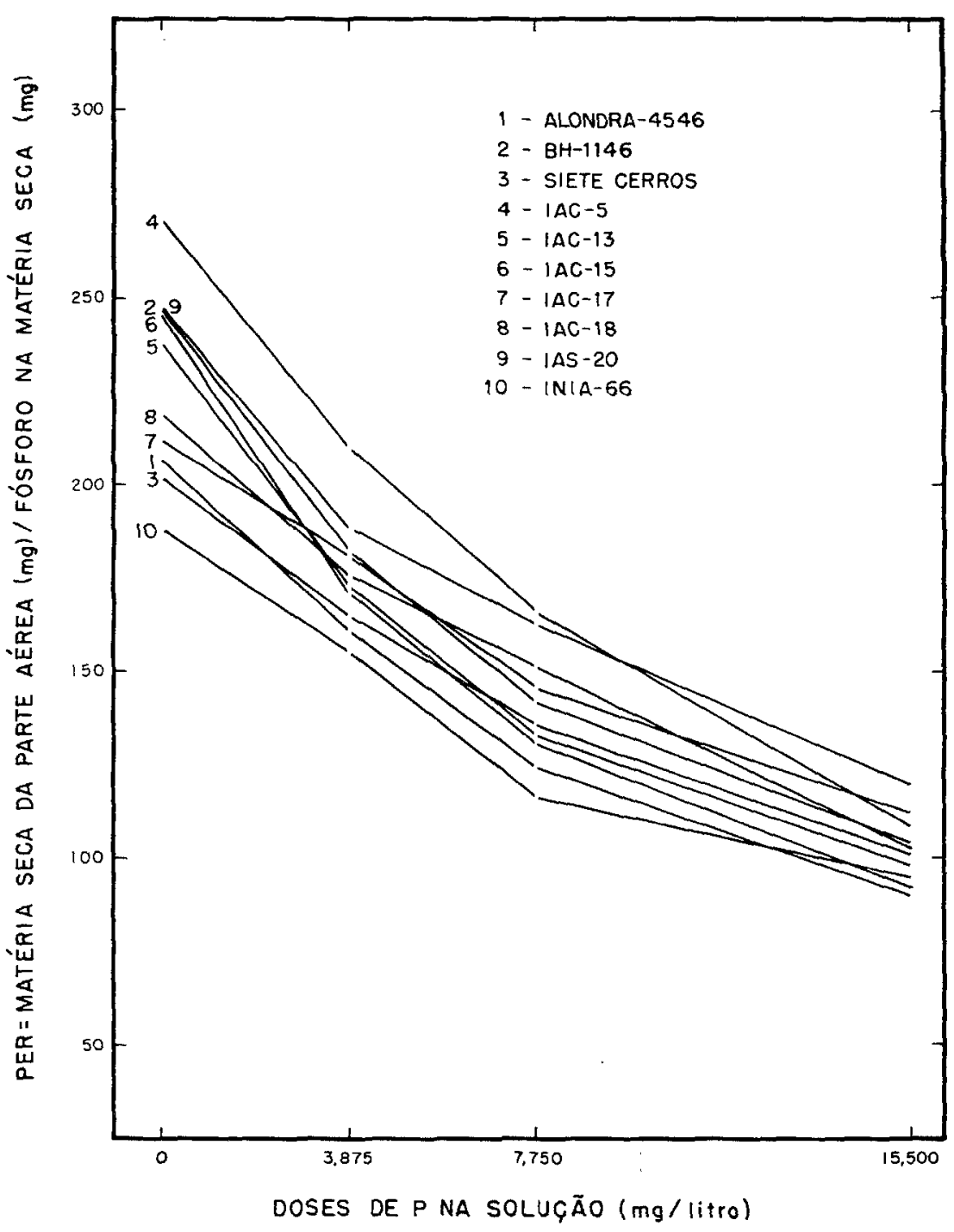

FIGURA 2 - Eficiência na utilização de $P$ (PER) medida pela relação entre 0 peso seco da parte aérea e a quantidade de fósforo presente neste tecido de trinta plantas de cada um dos dez cultivares de trigo estudados durante quinze dias em soluçōes nutritivas contendo $0 ; 3,875 ; 7,75$ e $15,5 \mathrm{mg} /$ hitro de $\mathrm{P}$. 
QUADRO 4 - Eficiência na utilização de $P$ (PER) medida pela relação entre o peso seco da parte aérea e a quantidade de fósforo presente neste tecido seco de trinta plantas de cada um dos dez cultivares de trigo estudados durante quinze dias em soluções nutritivas contendo $0 ; 3,875 ; 7,75$ e $15,5 \mathrm{mg} /$ litro

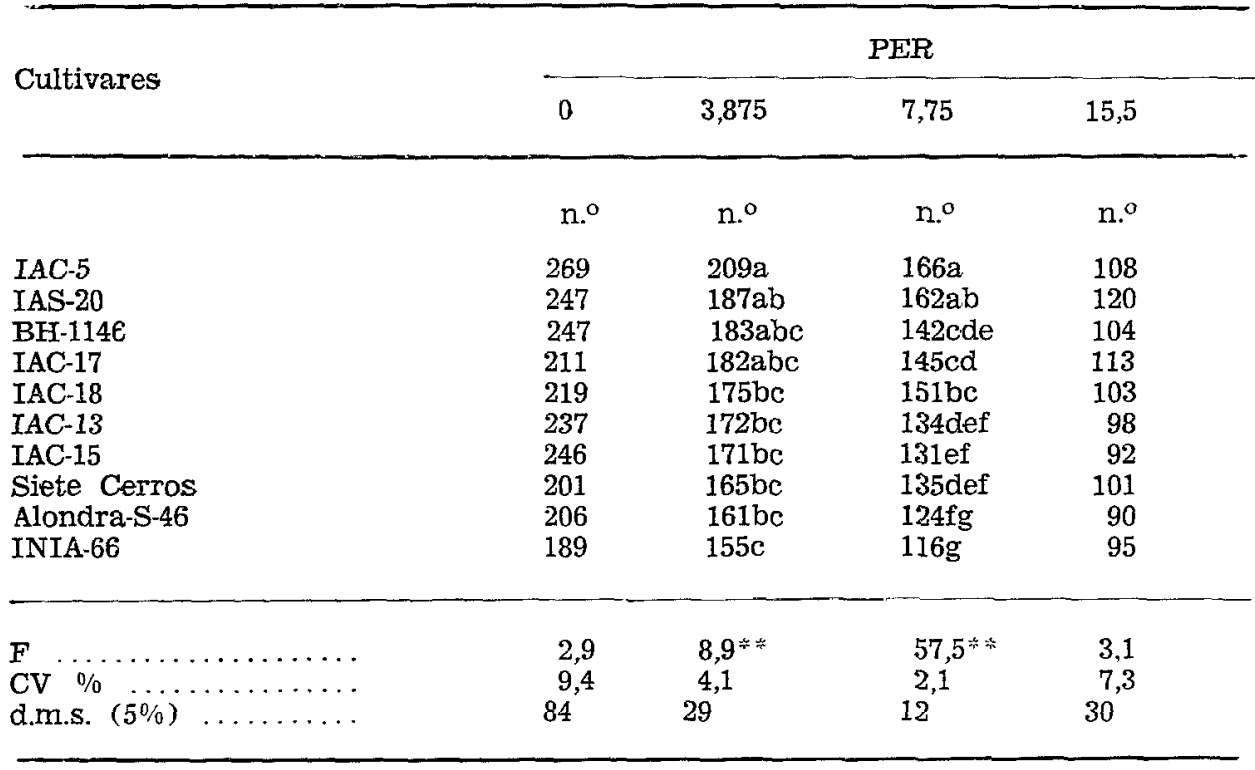

As médias dos cultivares, para as diferentes concentraçōes de fósforo esiudadas, seguidas de uma mesma letra, não diferen entre si.

Não foram observadas diferenças significativas pelo teste de Tukey entre os cultivares de trigo em relação ao PER (peso seco da parte aérea em miligrama dividido pela quantidade em $\mathrm{P}$ em miligrama na matéria seca da parte aérea ), quando foram utilizados 0 e $15,5 \mathrm{mg} /$ litro de $\mathrm{P}$ nas soluções.

Considerando a concentração de $3,875 \mathrm{mg} /$ litro de $\mathrm{P}$ na solução, o cultivar IAC-5 foi o que apresentou maior valor de PER, diferindo dos cultivares IAC-18, IAC-13, IAC-15, Siete Cerros, Alondra-S-46 e INIA-66, não diferindo, porém, pelo teste de Tukey a $5 \%$ dos cultivares IAS-20, BH-1146 e IAC-17. Na concentração de 7,75mg/litro de P, o 'IAC-5' apresentou também o maior índice de PER, não diferindo do cultivar IAS-20, porém diferindo dos demais.

Com base nos resultados obtidos e levando em consideração a produção de matéria seca, a proporção de eficiência na utilização de $P$, as respostas na produção de matéria seca à medida que se aumentavam as concentrações de $\mathrm{P}$ das soluções, foi possível diferenciar os 
cultivares de trigo nas seguintes categorias: eficientes na utilização do P : IAC-5, BH-1146, IAS-20 e IAC-17; moderadamente eficientes: IAC-18, IAC-13 e IAC-15, e ineficientes: Siete Cerros, INIA-66 e Alondra-S-46. Por outro lado, os cultivares IAC-5, IAC-18 e INIA-66 responderam mais à aplicação de doses crescentes de $P$ na solução; IAS-20, IAC-13, Siete Cerros e Alondra-S-46 apresentaram moderada resposta, e BH-1146, IAC-17 e IAC-15 não responderam.

Esses resultados sugeriram que é possível ter em um mesmo genótipo os fatores combinados responsáveis pela eficiência da utilização de fósforo em condições de baixa disponibilidade desse elemento e pela capacidade de resposta a altos níveis de disponibilidade. O cultivar IAC-5 seria uma boa fonte dessas características para um programa de melhoramento genético.

\subsection{Ensaio de cultivares de trigo em vasos}

As produções médias de matéria seca da parte aérea das sete plantas dos cultivares IAC-5 e IAC-17, aos trinta dias após a germinação, le os teores médios de $\mathrm{P}, \mathrm{K}, \mathrm{Ca}, \mathrm{Mg}$ e $\mathrm{Al}$ em porcentagem e em miligrama nessa matéria seca, no ensaio em condição de vasos, utilizando solo da Estação Experimental de Itararé com aplicação de doses de calcário combinadas com doses de $\mathrm{P}_{2} \mathrm{O}_{\tilde{n}}$, encontram-se nos quadros 5 e 6 e figuras 3,4 e 5 .

As produções de matéria seca da parte aérea das plantas do IAC-5 foram superiores às do IAC-17, diferindo em todos os tratamentos pelo teste de Tukey ao nível de $5 \%$, indicando ser o IAC-5 mais eficiente na utilização do fósforo absorvido do solo.

Os dois cultivares responderam à adubação com $\mathrm{P}_{2} \mathrm{O}_{5}$ para os três níveis de calagem em relação à produção de matéria seca da parte aérea, porém as respostas do IAC-5 foram maiores, confirmando os resultados anteriores em solução nutritiva.

Em relação ao teor de fósforo em porcentagem e em miligrama na rnatéria seca, o IAC-5 apresentou os maiores valores sugerindo ser mais eficiente na absorção de $\mathbf{P}$ do solo em níveis mais baixos desse elemento.

O IAC-5, sendo tolerante ao $\mathrm{Al}^{3+}$ tóxico existente no solo, não mostrou grande variaçāo nos teores desse elemento em porcentagem nos tecidos, mesmo nos diferentes tratamentos envolvendo doses crescentes de calcário e $\mathrm{P}_{2} \mathrm{O}_{5}$; por outro lado, o IAC-17, sendo moderadamente tolerante ao $\mathrm{Al}^{3+}$ tóxico, apresentou maior absorção desse elemento pela planta no tratamento sem calagem e sem aplicação de $\mathrm{P}_{2} \mathrm{O}_{\overline{3}}$, mas esses teores diminuíram pela aplicação quer do calcário, quer do $\mathrm{P}_{2} \mathrm{O}_{5}$. 


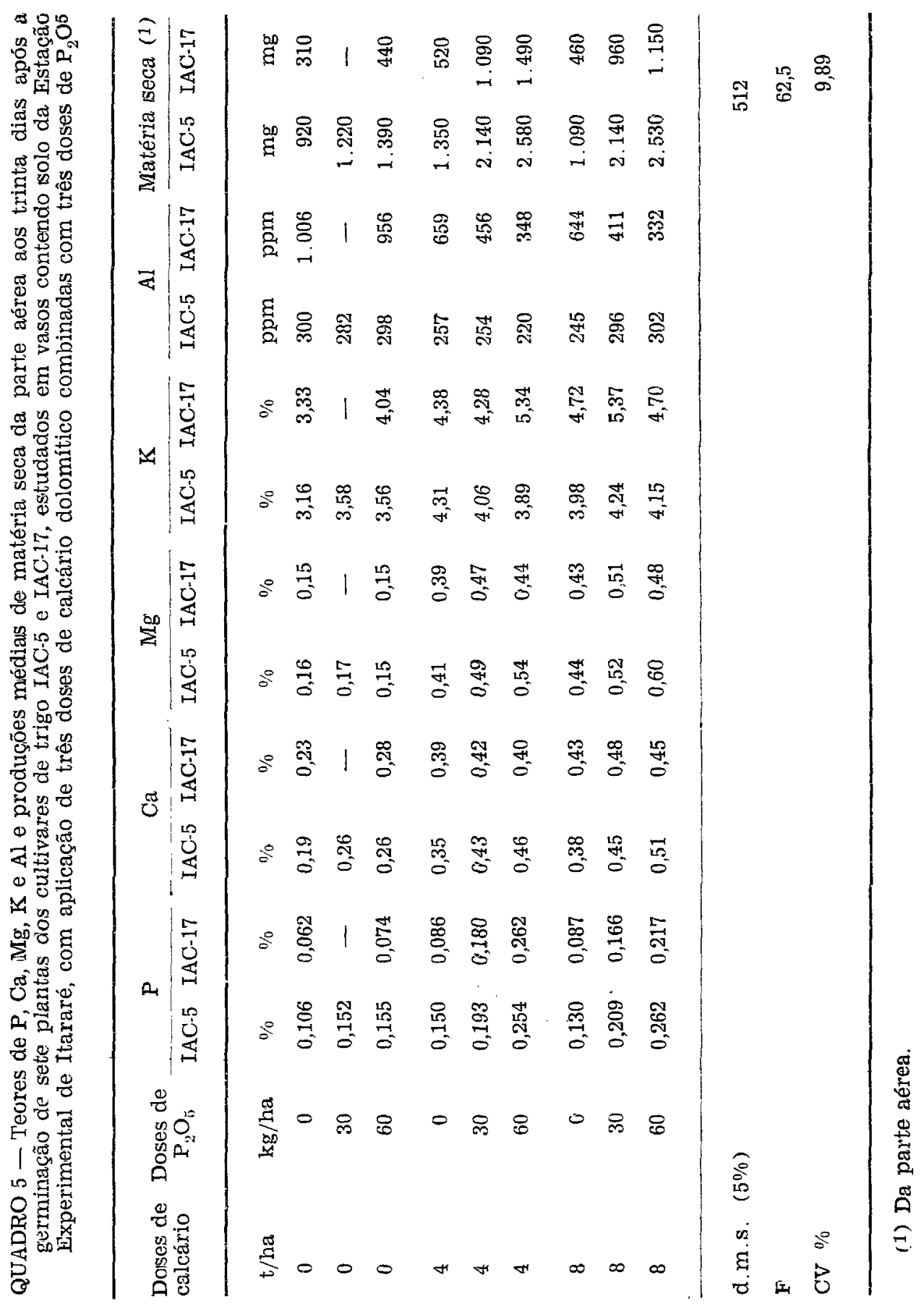




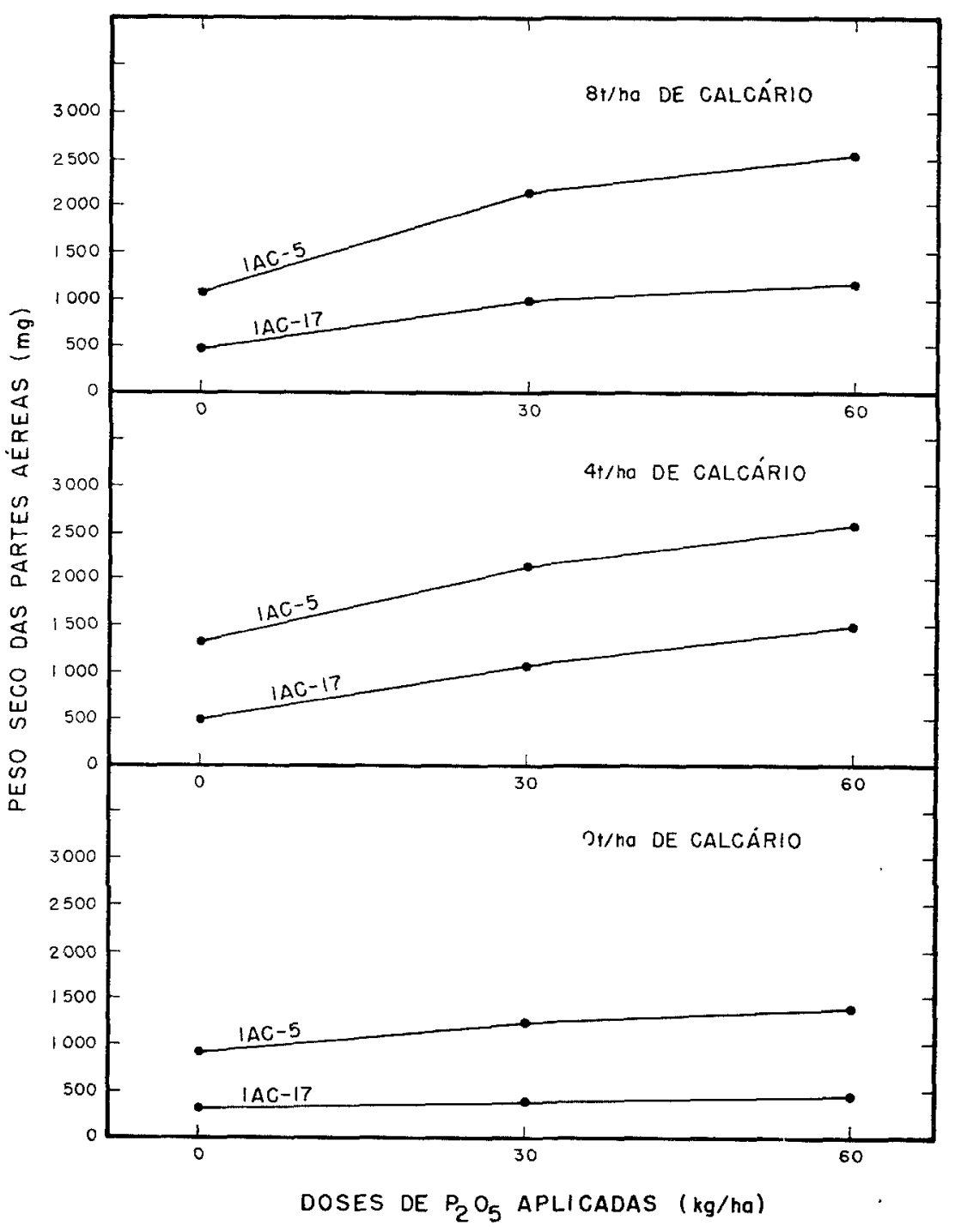

FIGURA 3 - Peso seco da parte aérea aos trinta dias após a germinação de sete plantas dos cultivares de trigo IAC-5 e IAC-17, estudados em vasos contendo solo da Estação Experimental de Itararé, com a aplicação de três doses de calcário dolomítico combinadas com três doses de $\mathrm{P}_{2} \mathrm{O}_{5}$. 


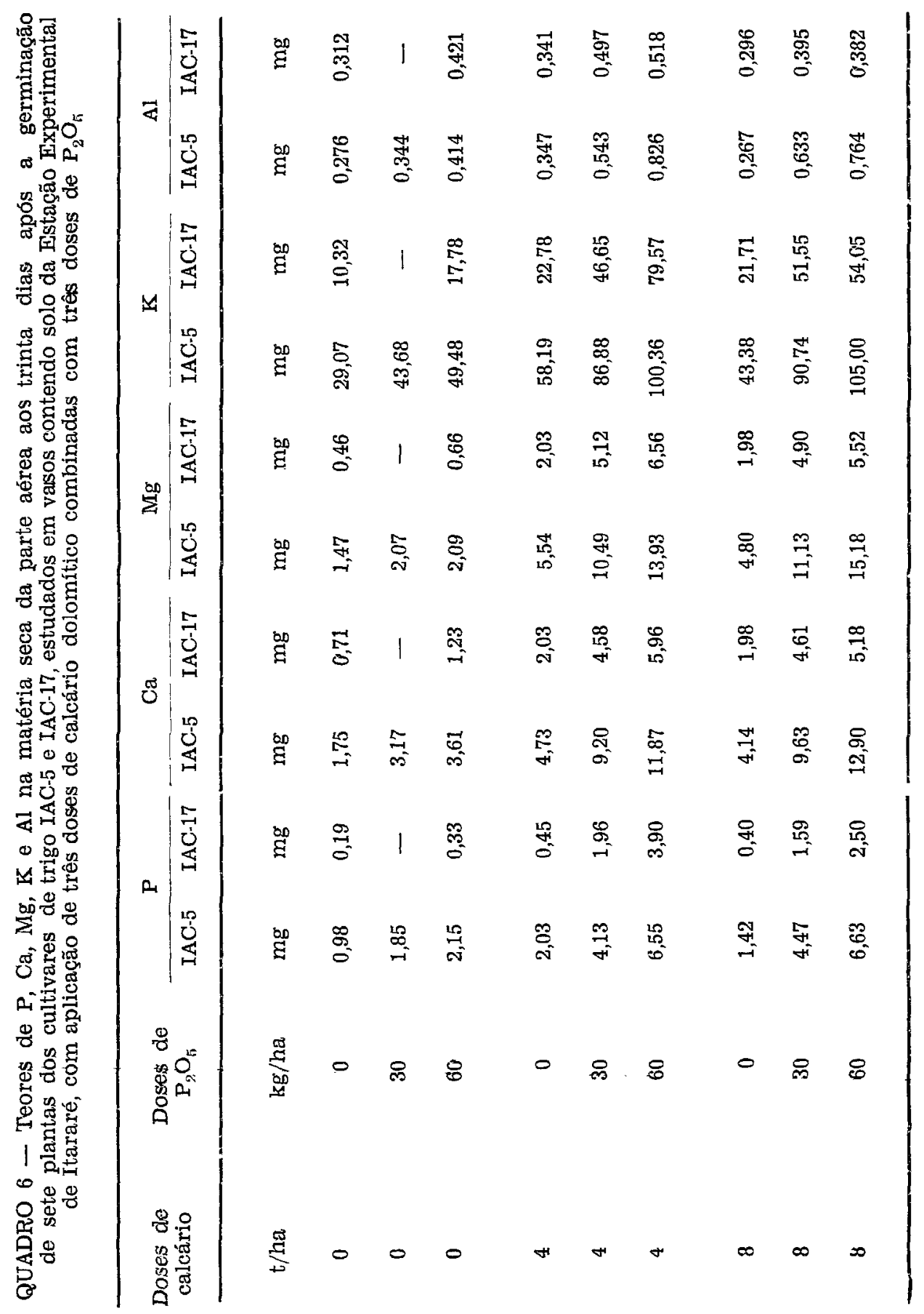




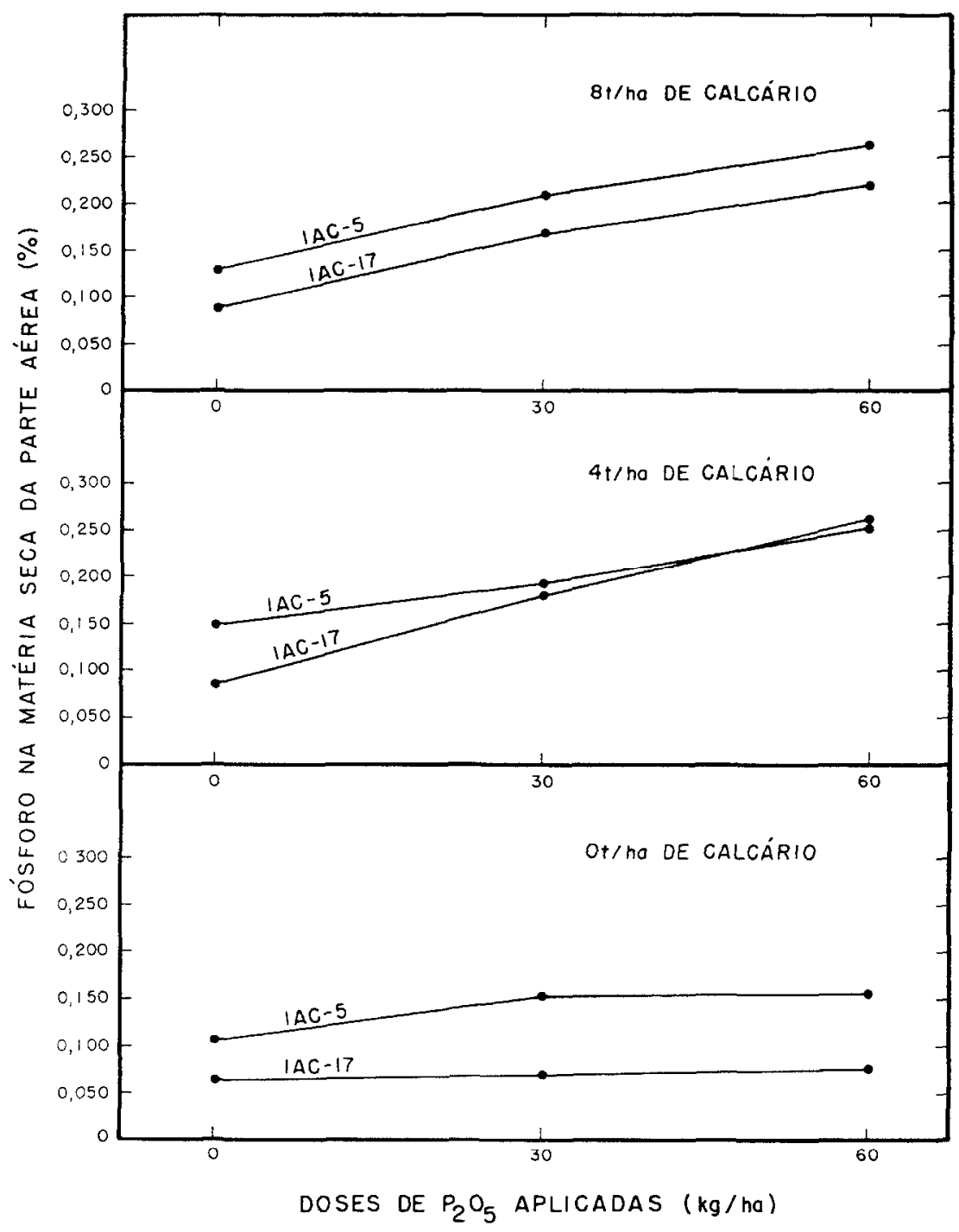

FIGURA 4 - Fósforo na matéria seca da parte aérea aos trinta dias após a germinação de sete plantas dos cultivares de trigo IAC-5 e IAC-17, estudados em vasos contendo solo da Estaçāo Experimental de Itararé, com a aplicação de três doses de calcário dolomítico combinadas com três doses de $\mathrm{P}_{2} \mathrm{O}_{5}$ 
Considerando fixo um mesmo nível de $\mathrm{P}_{2} \mathrm{O}_{5}$, verificou-se que os dois cultivares responderam à aplicação de calcário dolomítico até a dosagem de $4 \mathrm{t} / \mathrm{ha}$.

Os teores de $\mathrm{Ca}, \mathrm{Mg}$ e $\mathrm{K}$ nas plantas dos cultivares estudados aumentaram até a dosagem de $4 \mathrm{t} / \mathrm{ha}$ de calcário, sendo que para o nível de 8/ha, independente do nível de $\mathrm{P}_{2} \mathrm{O}_{\bar{v}}$ aplicado, houve tendência para pequenos aumentos ou até constância dos seus valores. Observando os pesos de $\mathrm{Ca}, \mathrm{Mg}$ e $\mathrm{K}$ em miligrama do 'IAC-5' em comparação com o 'IAC-17', verifica-se que cada planta do IAC-5 retirou uma quantidade muito maior desses elementos do solo, mostrando-se, portanto, mais eficiente na absorção e com maior adaptação às condições do solo estudado.

A produção de grãos por planta (Figura 6), altura da planta, número de espigas por planta, número de espiguetas por espiga, número de grãos por espiga, número de grãos por espigueta e comprimento da espiga dos cultivares de trigo estudados em condições de vasos contendo solos com diferentes tratamentos, encontram-se no quadro 7 .

O cultivar IAC-5 mostrou respostas em produção de grãos até a dose de $30 \mathrm{~kg}$ de $\mathrm{P}_{2} \mathrm{O}_{5} /$ ha para os três níveis de calcário. Para o nível de $60 \mathrm{~kg} /$ ha de $\mathrm{P}_{2} \mathrm{O}_{\bar{n}}$, mostrou tendência à diminuição de produção, evidenciando a existência de um não-balanceamento entre os teores de $\mathrm{Ca}$, $\mathrm{Mg}$ e $\mathrm{K}$ no solo estudado.

O IAC-17 produziu menos que o IAC-5 nos níveis de 0 e $30 \mathrm{~kg} / \mathrm{ha}$ de $\mathrm{P}_{2} \mathrm{O}_{5}$, independente das dosagens de calcário, e apresentou aumento de produção até a dosagem de $60 \mathrm{~kg} /$ ha de $\mathrm{P}_{2} \mathrm{O}_{5}$ nos vasos sem calcário, evidenciando que parte do fósforo aplicado no solo ficou associada ao alumínio, tornando-o menos disponível às plantas desse cultivar e, portanto, proporcionando-lhes melhor desenvolvimento. Para os tratamentos com 4 e $8 \mathrm{t}$ de calcário/hectare, o NAC-17 somente respondeu em produção até a dosagem de $30 \mathrm{~kg} / \mathrm{ha}$ de $\mathrm{P}_{2} \mathrm{O}_{5}$.

Entre os caracteres agronômicos estudados nos diferentes níveis de calagem e $\mathrm{P}_{2} \mathrm{O}_{5}$, mostraram diferenças significativas os seguintes: altura da planta, número de espiguetas por espiga, número de grãos por espiga e espigueta e comprimento da espiga.

Os tratamentos que apresentaram plantas com maior produção de grãos dos dois cultivares estudados estavam associados com plantas mais altas, com maior número de espigas, maior número de espiguetas, maior número de grãos por espiga e espigueta e espigas mais longas. 


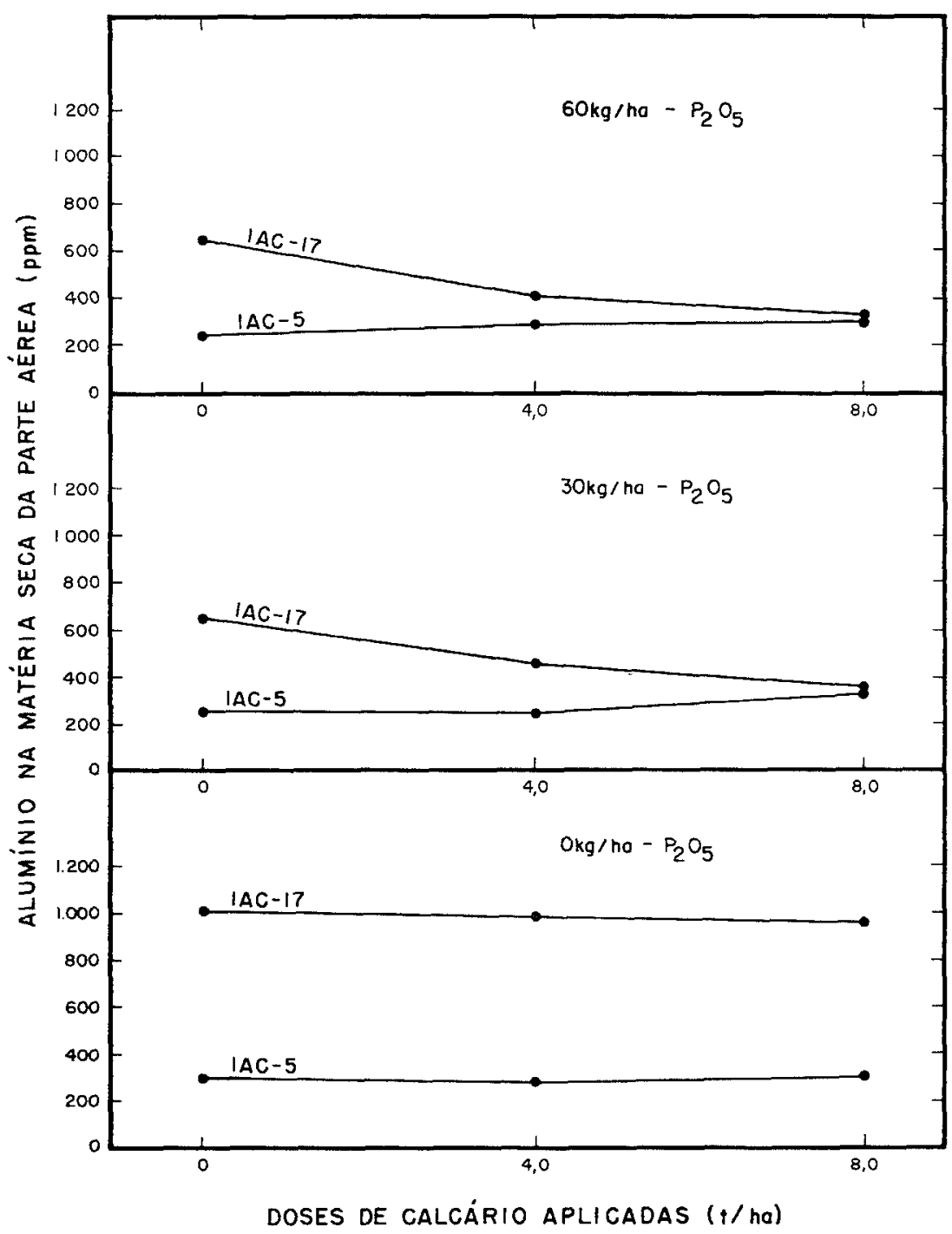

FIGURA 5 - Aluminio na matéria seca da parte aérea aos trinta dias após a germinação de sete plantas dos cultivares de trigo IAC-5 e IAC-17, estudados em vasos contendo solo da Estação Experimental de Itararé, com a aplicação de três doses de calcário dolomítico combinadas com três doses de $\mathrm{P}_{2} \mathrm{O}_{5}$. 


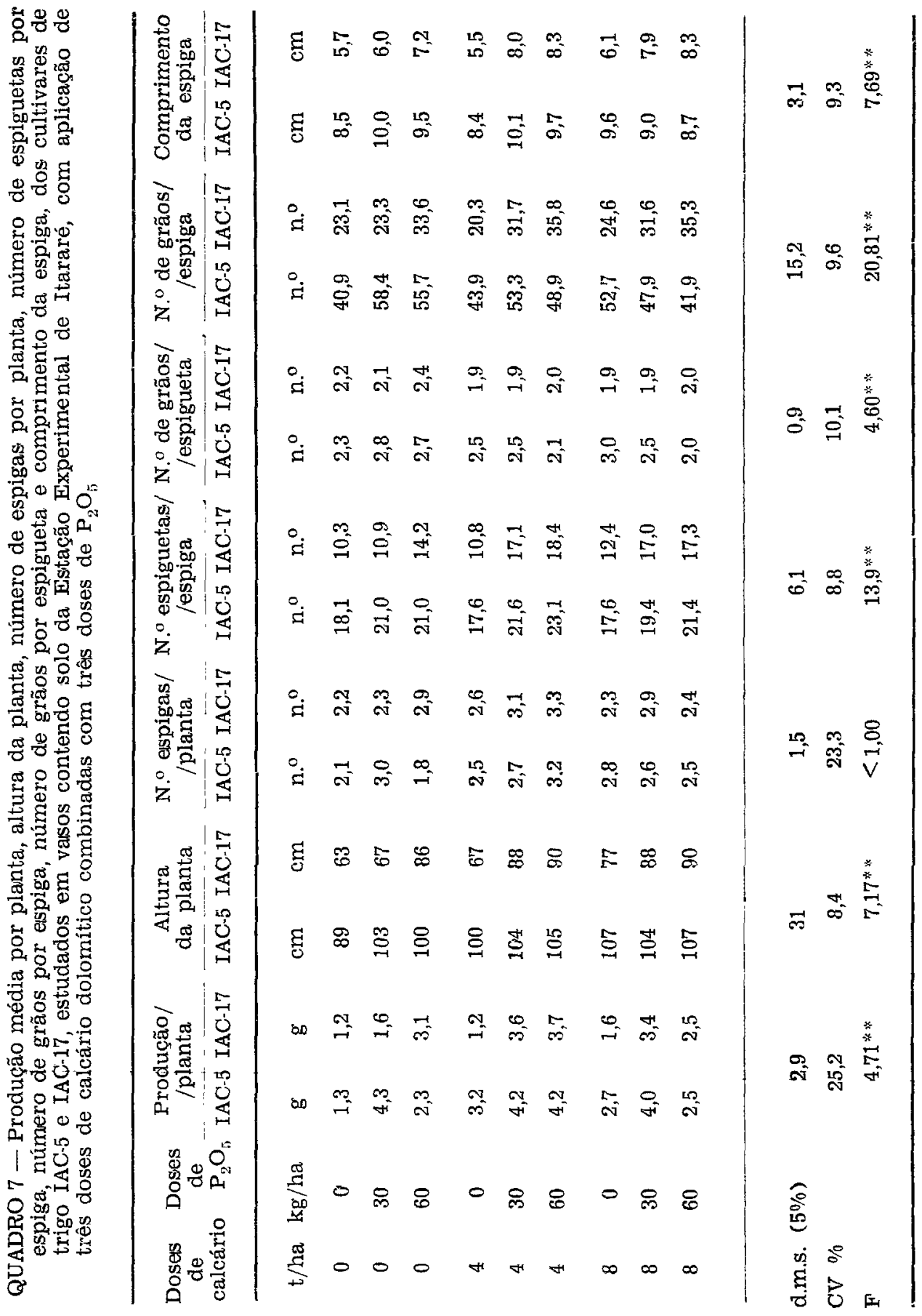




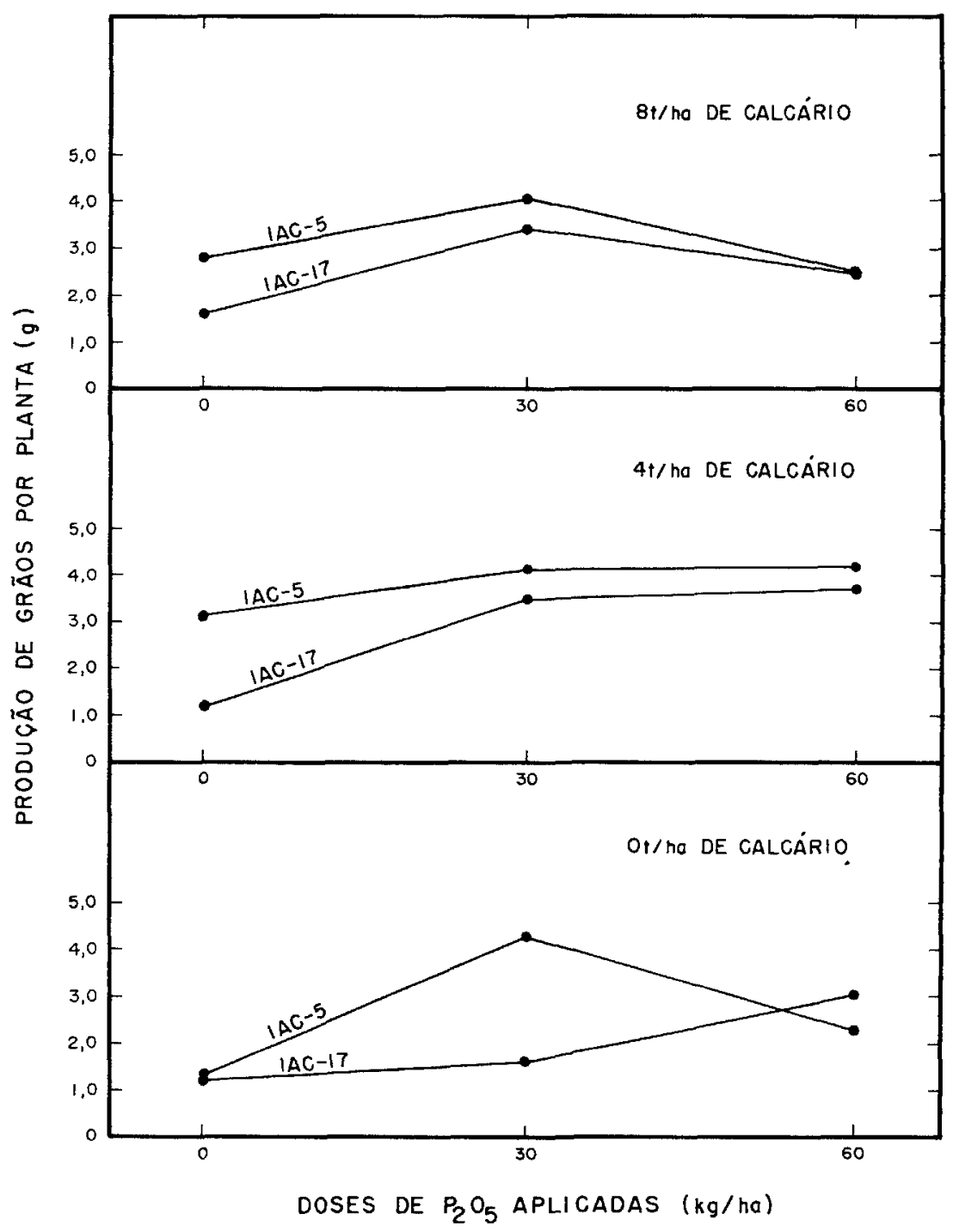

FIGURA 6 - Produção đe grãos por planta dos cultivares de trigo IAC-5 e IAC-17, estudados em vasos contendo solo da Estação Experimental de Itararé, com a aplicação de três doses de calcário dolomítico combinadas com três doses de $\mathrm{P}_{2} \mathrm{O}_{5}$. 


\section{CONCLUSÕES}

a) A técnica empregada para o estudo diferencial de cultivares de trigo em relação à eficiência da utilização de fósforo em soluções nutritivas contendo baixos níveis desse elemento, foi de utilidade, possibilitando a separação de cultivares eficientes e não-eficientes em quinze dias.

b) A presença de níveis crescentes de fósforo nas soluçōes nutritivas permitiu, em curto período de tempo, avaliar os cultivares que respondiam ou não à aplicação de doses maiores desse elemento.

c) Os cultivares IAC-5, IAS-20, BH-1146 e IAC-17 foram considerados eficientes na utilização de fósforo; IAC-18, IAC-13 e IAC-15, moderadamente eficientes, e Siete Cerros, INIA-66 e Alondra-S-46, ineficientes levando-se em consideração a produção de matéria seca da parte aérea e a proporção entre a produção de matéria seca da parte aérea e a quantidade de $\mathbf{P}$ nela presente para as soluções contendo $3,875 \mathrm{mg} /$ litro de $P$.

d) Os cultivares IAC-5, IAC-18 e INIA-66 responderam em produção de matéria seca da parte aérea à medida que foi aumentado de 0 a 15,5mg/litro o teor de P das solucões; IAS-20, IAC-13. Siete Cerros e Alondra-S-46 apresentaram moderada resposta, e BH-1146, IAC-17 e IAC-15 não mostraram resposta.

e) Os cultivares IAC-5 e IAC-17, em condição de solo, responderam à adubação com $\mathrm{P}_{2} \mathrm{O}_{\overline{1}}$ para os três níveis de calagem em relacão à produção de matéria seca da parte aérea, aos trinta dias da germinação, porém as respostas do IAC-5 foram maiores.

f) Sendo o 'IAC-17' moderadamente tolerante à toxicidade, devido ao $\mathrm{Al}^{3+}$ do solo, e 'IAC-5' tolerante, o primeiro. comparado com o segundo, nos tratamentos sem calagem, mostrou altos teores de Al nas folhas aos trinta dias da germinacão associados à baixa produção de matéria seca da parte aérea. Esses valores de $\mathrm{Al}$ nas folhas tenderam a diminuir à medida que foram adicionados 4 ou 8t/ha de calcário.

g) Os dois cultivares aumentaram a produção de grãos quando foram aplicadas doses crescentes de $\mathrm{P}_{2} \mathrm{O}_{5}$, mantendo-se constante a dose de calcário de $4 \mathrm{t} / \mathrm{ha}$, porém as grandes resnostas ocorreram auando foram comparadas as dosagens de 0 e $30 \mathrm{~kg} / \mathrm{ha}$ de $\mathrm{P}_{2} \mathrm{O}_{5}$, independente da quantidade de calcário aplicada.

h) O 'IAC-5', sendo eficiente na utilizacão e absorcão de fósforn em baixas concentrações desse elemento na solucão nutritiva $\odot$ no solo. pnderia ser cultivado em solos onde houvesse baixa disponibilidade de fósforo e. à medida que a concentracão desse elemento aumentasse nor práticas de adubação fosfatada, o cultivar responderia aumentando a nrodutividade. 


\section{SUMMARY}

\section{EFFECT OF DIFFERENT LEVELS OF PHOSPHORUS IN NUTRIENT SOLUTION AND IN THE SOIL ON THE RESPONSES OF WHEAT CULTIVARS}

Ten wheat cultivars were studied in nutrient solution with four different levels of phosphorus $(0 ; 3.875 ; 7.75$ and $15.5 \mathrm{mg} /$ liter $), \mathrm{pH}$ of 4.0 , temperature of $25^{\circ} \mathrm{C} \pm 1{ }^{\circ} \mathrm{C}$, during fifteen days. To express efficiency of $\mathrm{P}$ utilization for each cultivar under a particular concentration of $\mathrm{P}$ in the solution, the aereal part dry weight of 30 plants were used and $P$ efficiency ratios (PER) calculated as $\mathrm{mg}$ of top dry weight yield per $\mathrm{mg}$ of $\mathrm{P}$ in the top tissue. The cultivars IAC-5, IAS-20, BH-1146 and IAC-17 were efficient in P utilization from nutrient solution containing low levels of ( $3.875 \mathrm{mg} /$ liter); IAC-18, IAC-15 and IAC-13 showed moderate efficiency and Siete Cerros, Alondra-S-46 and INIA-66 were considered as non efficient cultivars. The cultivars IAC-5, IAC-18 and INIA-66 showed responses for top dry weight yield as the $P$ concentration increased from 0 to $15.5 \mathrm{mg} / \mathrm{liter}$. IAS-20, IAC-13, Siete Cerros and Alondra-S-46 presented moderate responses and BH-1146, IAC-17 and IAC-15 were considered as non responders. The cultivans IAC-5 and IAC-17 were planted in pots containing acid soil presenting high levels of organic metter and toxic aluminum associated with low disponibility of bases ard phosphorus. Three levels of $\mathrm{P}_{2} \mathrm{O}_{5}$ as fertilizers $(0,30$ and $60 \mathrm{~kg}$ per hectare) were used combined with three levels of lime $(0,4$ and 8 tons per hectare). Both cultivars showed responses to $\mathrm{P}_{2} \mathrm{O}_{5}$ fertilizer at the three levels of lime for top dry weight of 30 plants were used and $P$ effciency ratios (PER) calculated higher responses. Under a fixed level of $\mathrm{P}_{2} \mathrm{O}_{5}$ both cultivars responded until the application of 4 tons of lime per hectare in relation to top dry weight yield. Grain yield responses were observed when different levels of $\mathrm{P}_{2} \mathrm{O}_{5}$ were applied in the presence of 4 tons of lime per hectare. The highest responses were observed when the levels of 0 and $30 \mathrm{~kg}$ of $\mathrm{P}_{2} \mathrm{O}_{5}$ per hectare were compared independent of lime application. IAC-5 presented as an efficient cultivar as far as $P$ utilization is concerned under soil and nutrient solution containing low levels of phosphorus. So the nutrient solution technique was useful compared with soil experiments to separate different genotypes in relation to efficiency of $\mathrm{P}$ utilization and to $\mathrm{P}$ responses.

\section{REFERENCIAS BIBLIOGRAFICAS}

1. Camargo, C. E. O. Adujoação do trigo. II. Experiências com N, P, K e S em Latossolo Vermelho-Escuro Orto, na Regiāo Sul do Estado de São Paulo. Bragantia, Campinas, 31:325-335, 1972.

2. - Adubação do trigo. IX. Interpretação econômica dos resultados obtidos em experimentos com $\mathrm{N}, \mathrm{P}, \mathrm{K}$ e S, em Latossolo Roxo no Estado de São Paulo. Bragantia, Campinas, 35:95-106, 1976.

3. — OLIVEIRA, O. F. Tolerância de cultivares de trigo a diferentes níveis de alumínio em solução nutritiva e no solo. Bragantia, Campinas, 40:21-31, 1981.

4. -; VEIGA, A. A.; PESSINI, A. L.; MONTEIRO, D. A. Adubação do trigo. VII. Experiências com N, P, K e S em diferentes tipos de solos do Estado de São Paulo. Bragantia, Campinas, 34:273-286, 1975.

5. GABELMAN, W. H. Genetic potencials in nitrogen, phosphorus and potassium efficiency. In: PROCEEDINGS OF WORKSHOP ON PLANT ADAPTATIONS TO MINERAL STRESS IN PROBLEM SOILS. Beltsville, Maryland, 1976. p. 205-212. 
6. GERLOFF, G. C. Plant efficiencies in the use of nitrogen, phosphorus, and potassium. In: PROCEEDINGS OF WORKSHOP ON PLANT ADAPTATIONS TO MINERAL STRESS IN PROBLEM SOILS. Beltsville, Maryland, 1976. p.161-173.

7. HOWELL, R. W. \& BERNARD, R. L. Phosphorus response of soybean varieties. Crop Science, 1:311-3i3, 1961.

8. LYNESS, A. S. Varietal differences in the phosphorus feeding capacity of plants. Plant Physiology, 1:665-688, 1936.

9. Oliveira, O. F.; CAMARGo, C. E. O.; RAMOS, V. J. Efeito de doses crescentes de fósforo na produção, altura, componentes de produção, em dois cultivares de trigo em Itararé (SP). Bragantia, Campinas, 43(1):31-44, 1984 .

10. WHITEAKER, G.; GERLOFF, G. C.; GABELMAN, W. H.; LINDGREN, D. Intraspecific differences in growth of beans at stress levels of phosphorus. Journal American Society for Horticultural Science, 101(4):472-475, 1976. 